\title{
Effect of bead milling on chemical and physical characteristics of activated carbons pulverized to superfine sizes
}

\author{
Erin Partlan ${ }^{\text {a }}$, Kathleen Davis ${ }^{\text {b }}$, Yiran Ren ${ }^{\text {a }}$, Onur Guven Apul a , O. Thompson Mefford ${ }^{\text {b }}$, \\ Tanju Karanfil a , David A. Ladner ${ }^{\text {a* }}$ \\ ${ }^{a}$ Department of Environmental Engineering and Earth Sciences, Clemson University, \\ 342 Computer Ct, Anderson, SC, 29625, USA. \\ ${ }^{\mathrm{b}}$ Department of Materials Science and Engineering, Clemson University, \\ 161 Sirrine Hall, Clemson, SC 29634, USA. \\ *Corresponding author: ladner@clemson.edu
}




\section{Abstract}

2 Superfine powdered activated carbon (S-PAC) is an adsorbent material with particle size

3 between roughly 0.1 to $1 \mu \mathrm{m}$. This is about an order of magnitude smaller than conventional

4 powdered activated carbon (PAC), typically 10 to $50 \mu \mathrm{m}$. S-PAC has been shown to outperform

5 PAC for adsorption of various drinking water contaminants. However, variation in S-PAC

6 production methods and limited material characterization in prior studies lead to questions of

7 how S-PAC characteristics deviate from that of its parent PAC. In this study, a wet mill filled

8 with $0.3-0.5 \mathrm{~mm}$ yttrium-stabilized zirconium oxide grinding beads was used to produce S-PAC

9 from seven commercially available activated carbons of various source materials, including two

10 coal types, coconut shell, and wood. Particle sizes were varied by changing the milling time,

11 keeping mill power, batch volume, and recirculation rate constant. As expected, mean particle

12 size decreased with longer milling. A lignite coal-based carbon had the smallest mean particle

13 diameter at $169 \mathrm{~nm}$, while the wood-based carbon had the largest at $440 \mathrm{~nm}$. The wood and

14 coconut-shell based carbons had the highest resistance to milling. Specific surface area and pore

15 volume distributions were generally unchanged with increased milling time. Changes in the point

16 of zero charge (pHpzc) and oxygen content of the milled carbons were found to correlate with an

17 increasing specific external surface area. However, the isoelectric point ( $\mathrm{pHIEP}$ ), which measures

18 only external surfaces, was unchanged with milling and also much lower in value than $\mathrm{pH}$ Pzc. It

19 is likely that the outer surface is easily oxidized while internal surfaces remain largely

20 unchanged, which results in a lower average $\mathrm{pH}$ as measured by $\mathrm{pH}$ pzc.

23 Keywords: activated carbon, pulverization, oxidation, $\mathrm{pH}$ shift, surface area, pore distribution 


\section{Introduction}

27 Activated carbon adsorption is a best available technology for the removal of small molecular 28 weight organic contaminants from water (Clark and Lykins, 1990; Crittenden et al., 2005a;

29 Osantowski and Wullschleger, 1986). Powdered activated carbon (PAC) is a common form of 30 activated carbon, produced by grinding larger granular activated carbon particles (GAC) (Neely

31 and Isacoff, 1982; Snoeyink and Chen, 1985). PAC is defined as particles passing through an 80-

32 mesh sieve $(177 \mu \mathrm{m})($ ASTM Standard D5158-98, 2013) but typical particle sizes are between 10

33 and $50 \mu \mathrm{m}$. A recent development in activated carbon technology is to further reduce the size of

34 PAC. Superfine powdered activated carbon (S-PAC) is activated carbon that has been reduced to 35 sizes near or less than one micrometer.

37 S-PAC can improve adsorption kinetics for small molecules and circumvents competition with 38 larger molecules, such as natural organic matter (NOM) (Ellerie et al., 2013; Heijman et al.,

39 2009a; Matsui et al., 2013, 2009). The mechanism for faster adsorption lies in shortened

40 diffusion-limited adsorption pathways, which allows faster transport to terminal adsorption sites

41 for small molecules (Ando et al., 2010; Ellerie et al., 2013; Matsui et al., 2008; Pelekani and

42 Snoeyink, 2000). Terminal sites for small molecules lie in micropores where sorption occurs due

43 to increased sorption strength for pore diameters less than twice an adsorbate diameter (Li et al.,

44 2002). Conversely, adsorption of large molecules is only governed by external surface area and

45 not by the characteristics of inner pores. In the shortened pathways of S-PAC, the time of

46 transport for small molecules is decreased, but the rate of large molecule adsorption to outer

47 surfaces and pores remains the same. The increase in the rate of large molecule adsorption due to 48 increased specific external surface area is much less than the increase in small molecule 
49 adsorption due to the shortened diffusion pathway. As a result, particle size is the main driving

50 force behind improved kinetics. However, changes in other physical and chemical properties can

51 also impact adsorption performance. For example, it is possible for pulverization to shift the

52 distribution of pore sizes by exposing smaller diameter pores, effectively becoming larger

53 diameter pores (Dunn and Knappe, 2013; Ellerie et al., 2013; Matsui et al., 2014). An in-depth

54 examination of carbon characteristics on adsorption performance revealed that carbon properties,

55 namely hydrophilicity in the form of oxygen content, had strong impacts on the penetration of

56 depth of adsorbates (Matsui et al., 2015).

58 Since S-PAC is not commercially available, there is no standard production method. Individual

59 groups have produced their own materials or outsourced their production on a case-by-case basis,

60 so material production parameters may vary widely. These parameters have been rarely reported

61 as there is no available guidance regarding parameters to be controlled and recorded. S-PAC

62 researchers describe production through wet milling using phrases such as wet grinding in a bead

63 mill, pulverization in a ball mill, wet mill micro-grinding and micro-grinding in a wet bead mill

64 (Ando et al., 2010; Ellerie et al., 2013; Heijman et al., 2009a; Matsui et al., 2007). Wet milling

65 generally encompasses high velocity contact between grinding media and the product material-

66 activated carbon in this case — while suspended in a carrier fluid. Grinding media can be made

67 from a variety of materials and in a variety of sizes; none of the previous studies specifically

68 describe the grinding media used. Additionally, the carrier fluid and additives such as surfactants

69 are not described, though many are available for enhancing grinding performance. The specific

70 outcome of grinding depends on these factors since it is the result of energy transfer from the

71 rotation of the mill through the grinding media and the carrier fluid. 
73 Among carbons, differences in abrasion resistance, also termed hardness, affect the rate of

74 particle breakdown. Abrasion is a surrogate measure of hardness since harder carbons have a

75 reduced tendency to degrade upon impact than softer carbons (Toles et al., 2000; Yalcin and

76 Arol, 2002). Activated carbons are relatively soft; commercial coal and wood based carbons

77 were found to have a Mohs hardness between 2 and 3 on the 1-10 Mohs hardness scale (Patni et

78 al., 2008). Carbon hardness depends on the carbon precursor. Coconut shell and other nut shells

79 are very hard precursors (Heschel and Klose, 1995; Mohd Din et al., 2009). Of coal carbons,

80 bituminous coal-based carbons are harder than lignite-based carbons (Greenbank and Spotts,

81 1993). Wood-based carbons have a much wider range of hardness, from softer than lignite coal-

82 based carbons to as hard as coconut-shell based carbons, depending on the type of wood

83 (Hernández et al., 2014).

84

85 Wet milling is designed to physically alter the carbon but may also cause chemical changes,

86 which is important for activated carbon applications since chemical characteristics play large

87 roles in adsorption processes (Karanfil and Kilduff, 1999; Karanfil et al., 1999; Li et al., 2002;

88 Quinlivan et al., 2005). Surface functional groups affect the type of molecules that are

89 preferentially adsorbed (Apul et al., 2015; Karanfil and Kilduff, 1999; Pendleton et al., 1997).

90 Carbon modification has been explored for enhanced or targeted contaminant removal (Akmil

91 Başar et al., 2003; Dastgheib et al., 2004; Liu et al., 2009). For example, oxidation of carbon

92 results in increased adsorption of metal cations but decreased adsorption of low molecular

93 weight organic compounds (Biniak et al., 1999; Jia and Thomas, 2000; Karanfil and Kilduff,

94 1999; Tessmer et al., 1997). Activated carbon typically has oxygen content around 3-4\% by 
95 mass; those modified to increase oxygen-containing functional groups can have contents around

96 10\% (Apul et al., 2013; Li et al., 2002).

97

98 Due to the small sample size of S-PACs in previous studies combined with limited

99 characterization data, trends in material changes as a result of PAC size reduction cannot be

100 determined. Most recently, Matsui et al. (2015) measured a large number of parameters

101 regarding milled carbons; however, the study measured properties of only one particle size and

102 did not examine changes as a result of milling. Hence, the main objective of this study was to

103 systematically examine a number of carbon types under varying degrees of milling in order to

104 elucidate specific effects of wet milling on the chemical and physical characteristics of activated 105 carbons.

\section{Materials and Methods}

\subsection{Activated Carbon}

108 Activated carbon materials were obtained from several commercial sources and chosen to cover

109 a range of characteristics. Seven commercial carbons were used with variation in specific surface

110 area, pore volume, and pHpZc: Watercarb-800 (bituminous coal, Standard Purification),

111 Filtrasorb 400 (bituminous coal, Calgon), PAC 20 B (bituminous coal, Norit), Hydrodarco 3000

112 (lignite coal, Norit), Hydrodarco B (lignite coal, Norit), Aqua Nuchar (wood, Mead Westvaco),

113 and Aquacarb 1230C (coconut shell, Siemens). The carbons are labeled as BC1, BC2, BC3, LC1,

114 LC2, WD, and CS, respectively (Table 1). BC1, BC3, LC2, and WD were received as PAC, and

115 they were sufficiently small to pass the $200 \mu \mathrm{m}$ mesh screen within the bead mill. LC1, BC2, and 
116 CS were received as GAC, and they were processed using a coffee grinder and sieved through a

$117 \quad \# 100$ screen (150 $\mu$ m openings) to isolate the smaller particles for milling.

123 Table 1: Measured characteristics of parent PAC materials: specific surface area, total pore 124 volume, and point of zero charge (pHpzc). Seven PACs were milled including coal, wood, and 125 coconut shell based materials.

\begin{tabular}{lllcccc}
\hline \hline $\begin{array}{c}\text { Origin } \\
\text { Material }\end{array}$ & Label & $\begin{array}{c}\text { Product } \\
\text { Name }\end{array}$ & $\begin{array}{c}\text { PAC } \\
\text { Size } \\
(\boldsymbol{\mu m})\end{array}$ & $\begin{array}{c}\text { Specific } \\
\text { Surface } \\
\text { Area }\left(\mathbf{m}^{2} / \mathbf{g}\right)\end{array}$ & $\begin{array}{c}\text { Specific Pore } \\
\text { Volume } \\
\left(\mathbf{c m}^{3} / \mathbf{g}\right)\end{array}$ & pHPZC \\
\hline Bituminous Coal & BC1 & Watercarb-800 & 12.3 & 644 & 0.35 & 10.37 \\
Bituminous Coal & BC2 & Filtrasorb 400 & 11.3 & 1038 & 0.67 & 8.65 \\
Bituminous Coal & BC3 & PAC 20 B & 13.6 & 880 & 0.48 & 9.79 \\
Wood & WD & Aqua Nuchar & 11.3 & 1676 & 0.89 & 6.20 \\
Coconut Shell & CS & Aquacarb 1230C & 11.3 & 1027 & 0.72 & 10.79 \\
Lignite Coal & LC1 & Hydrodarco 3000 & 12.8 & 660 & 0.61 & 5.39 \\
Lignite Coal & LC2 & Hydrodarco B & 13.5 & 505 & 0.39 & 11.40 \\
\hline \hline
\end{tabular}

\section{$127 \quad 2.2 \quad$ Bead Mill}

128 PAC was pulverized to S-PAC using a bead mill (MiniCer, Netzsch Premier Technologies,

129 Exton, PA, USA) containing 0.3-0.5 mm yttrium-stabilized zirconium oxide ceramic beads. The

130 mill was operated at $85 \%$ loading capacity; $120 \mathrm{~mL}$ of beads were measured with a graduated

131 cylinder and added to the $140 \mathrm{~mL}$ mill. Thus, the design mill void was $20 \mathrm{~mL}$, but the total mill

132 void was $50 \mathrm{~mL}$ after accounting for void space when measuring the beads. The $120 \mathrm{~mL}$ loading

133 volume corresponds to approximately 2 million beads. PAC was added to the mill as a slurry

134 comprised of 24 grams of dry carbon in $300 \mathrm{~mL}$ of distilled and deionized water (DDI) with 18 
$135 \mathrm{M} \Omega$ resistivity, yielding a percent solids concentration of approximately $6-7 \%$. The slurry was

136 kept chilled at $10^{\circ} \mathrm{C}$ during milling.

138 It is common in milling applications to use a dispersant to aid the milling process. Without

139 dispersants the breakup of particles results in an increase in solution viscosity; dispersants help

140 maintain fluidity and decrease pumping energy. One dispersant type (Reax, Mead Westvaco)

141 was tested to evaluate its effects on carbon milling; however, all of the samples used for further

142 characterization were milled with no dispersant addition.

144 All S-PAC samples were produced using the same flow rate, mill loading, and mill rotational

145 speed; thus, the rate of energy transfer to the carbon particles was kept constant through all tests.

146 Total energy applied was varied by changing the total milling time, which varied from one pass

147 through the mill to six hours. In the one-pass scenario carbon was fed into the mill and then

148 collected as product in the output. This was repeated once more for the two-pass scenario. Each

149 pass took approximately 45 seconds. In all other millings, the carbon slurry was recirculated

150 through the system by connecting the output line back to the feed tank.

\section{$151 \quad 2.3 \quad$ Characterization Methods}

152 Milled and unmilled carbons were analyzed for physical and chemical parameters. Elemental

153 analysis, measuring weight percent compositions of carbon, oxygen, hydrogen, and nitrogen, was

154 performed using a Flash Elemental Analyzer 1112 series (Thermo Electron Corporation). Sizes

155 for particles less than $6 \mu \mathrm{m}$ in diameter were measured using dynamic light scattering (DLS)

156 with a Zetasizer NanoZS (Malvern, Worcestershire, UK). Readings were taken in distilled water

157 after bath sonication and Z-avg hydrodynamic diameters are reported. Particles larger than $6 \mu \mathrm{m}$ 
158 were measured by optical microscopy imaging using a Zeiss Axioskop 2 Plus optical microscope

159 with a Zeiss AxioCam MRc5 camera attachment running AxioVision AC version 4.2 software.

160 Particles were sonicated in DDI before imaging and Zeiss Immersionsol 518C immersion oil was

161 used to view the particles at 40x magnification. The images were processed using ImageJ

162 software to determine the average Feret diameter of the particles and the particle size

163 distribution. Particles were also visually observed with scanning electron microscopy (SEM,

164 Hitachi SU6600) after sputter coating with platinum for 3-minutes.

165

166 Nitrogen gas adsorption was performed at $77 \mathrm{~K}$ with an ASAP 2020 analyzer (Micromeritics

167 Instrument Corp. U.S.) and pore size distributions were determine using density functional

168 theory (DFT) and calculated surface area from the Brunauer-Emmett-Teller (BET) equation. The

169 DFT model allows for categorization of pore volumes into micropore $(<2 \mathrm{~nm})$, mesopore $(2-50$

$170 \mathrm{~nm})$, and macropore $(>50 \mathrm{~nm})$ fractions.

171

$172 \mathrm{pH}$ pzC in the bulk material was measured by a $\mathrm{pH}$ drift method where the point of zero charge is

173 defined as the $\mathrm{pH}$ were no drift occurs after 48 hours (Dastgheib et al., 2004; Lopez-Ramon et

174 al., 1999). For each $\mathrm{pH}$ point and carbon, $100 \mathrm{mg}$ of dry carbon were added to $20 \mathrm{~mL} \mathrm{of} \mathrm{pH}$

175 adjusted $0.1 \mathrm{M} \mathrm{NaCl}$ in a $\mathrm{CO}_{2}$-free atmosphere in a glove box. After a minimum of 48 hours on a

176 shaker table, $\mathrm{pH}$ was measured in each vial and compared to a no carbon blank. The isoelectric

177 point ( $\mathrm{pH}$ IEP) of the carbon was determined by measuring the zeta potential of S-PACs using the

178 Zetasizer NanoZS (Malvern, Worcestershire, UK) and observing the $\mathrm{pH}$ that produced a zeta

179 potential reading of zero. Samples were prepared by probe sonication in DDI and manually

180 titrated for $\mathrm{pH}$ adjustment. 


\section{Results and Discussion}

\section{$3.1 \quad$ Milling}

183 Each pass through the mill corresponded with approximately 5 seconds of contact time through

184 the $50 \mathrm{~mL}$ mill void. Thus, a milling time of 30 minutes corresponded to approximately 40

185 passes through the mill and a total milling time of 200 seconds, based on average residence time.

186 However, due to short circuiting and dead zones within the mill feed tank, the true number of

187 passes was likely higher for some particles and lower for others. Additionally, viscosity

188 increased at different rates for each carbon, so the number of passes made by one carbon may

189 differ slightly from the number made by a different carbon due to a changing flow rate. DDI was

190 added as needed during milling to decrease viscosity and allow for complete mixing.

192 To examine the effect of dispersant on milling, WD was milled with varying dispersant

193 concentrations. Dispersant mitigated viscosity increase, reducing the need to add DDI, and did

194 not affect the particle size reduction. Notably, the coconut shell-based carbon, CS, did not

195 noticeably increase in viscosity though no dispersant was added. As mentioned previously, none

196 of the samples milled with dispersants were used for further characterization in this study.

\section{$197 \quad 3.2 \quad$ Carbon Particle Size}

198 PAC particle sizes were very similar among carbons, with median sizes ranging from 11 to 14

$199 \mu \mathrm{m}$ (Table 1). Milling times as brief as one pass through the mill resulted in particle sizes near or

200 below one micrometer and subsequent milling further reduced median particle sizes but with

201 diminishing returns (Figure 1). Due to the different analytical measurements for determining 
202 particle size above and below 6 micrometers - DLS for smaller particles and visible-light 203 microscope image analysis for larger ones - comparison of S-PAC size with parent PAC is

204 indirect. The hydrodynamic diameter measurements from DLS are found using models that 205 assume spherical shape. The spherical assumption is supported by SEM images, especially for 206 particles milled for longer times, but particles milled for shorter times have more angularity.

207 SEM also qualitatively supports Z-avg particle size measurements with observable declines in 208 particle size as milling time increases. Images of PAC and all S-PACs from BC1 taken by SEM 209 at 10,000 times magnification reveal the range of particle sizes from large PAC and 1 pass 210 particles to small particles after $6 \mathrm{hrs}$ that have a tendency to aggregate (Figure 2). The smallest 211 particles - after $1 \mathrm{hr}, 2 \mathrm{hrs}$, and $6 \mathrm{hrs}$ - were also imaged at 20,000 times magnification where 212 individual particles are more clearly identifiable (Figure S1).

214 The longest milling times resulted in the smallest particle sizes for each carbon. Most carbons 215 reduced to median particle sizes of $200-400 \mathrm{~nm}$; the largest size was $440 \mathrm{~nm}$ for WD after 6 216 hours of milling and the smallest was LC2 at $170 \mathrm{~nm}$ after 4 hours of milling (Figure 1). In 217 addition to producing the smallest S-PAC, LC2 also had the largest reduction in size in the 218 shortest time; particles had a median size of $342 \mathrm{~nm}$ after 5 minutes and $270 \mathrm{~nm}$ after 20 219 minutes. The second lignite-based carbon, LC1, also exhibited relatively fast size reduction 220 resulting in a median size of $390 \mathrm{~nm}$ after 15 minutes; however, it did not continue decreasing in 221 size with further milling, with a size of $324 \mathrm{~nm}$ after 6 hours. WD, BC2, and CS had little 222 particle breakdown under short milling times, with median sizes above $700 \mathrm{~nm}$ and up to 1000 $223 \mathrm{~nm}$ in the case of WD after one pass through the mill. 
225 Overall, CS and WD were the slowest to decrease in size during milling, as seen by a low slope

226 in its concentration over milling time (Figure 3). Concentration was calculated from number-

227 based particle size distributions measured in triplicate and conservation of mass; particle

228 volumes calculated from the distribution bins were divided into the total initial mass to arrive at a

229 total particle number. LC2 had the fastest breakdown (i.e. the fastest increase in particle

230 concentration), followed by $\mathrm{BC} 3$, while $\mathrm{BC} 1, \mathrm{BC} 2$, and $\mathrm{LC} 1$ had similar rates. Rates of

231 breakdown are interpreted as ease of milling - faster breakdown rates correspond to softer

232 carbons that are more easily milled.

233

234 The particle size results indicate that the same milling energy has different effects for different

235 carbons. The three bituminous coals exhibited similar milling responses. The lignite coals acted

236 similarly at first, but one continued to decrease in particle size while the other leveled off. Both

237 WD and CS remained as large particles after initial milling, though CS responded to continued

238 milling while WD did not. Thus, the rates of particle breakdown as well as the minimum

239 achievable particle size were highly specific to each carbon and generalizations based on

240 material are difficult to draw.

\section{$242 \quad 3.3 \quad$ Carbon Chemical Properties}

243 The majority of PACs had a basic pHPzC, though WD was neutral and LC1 had an acidic pHPZC.

244 As milling time increased, the pHPZC of all carbons decreased and the oxygen content of all

245 carbons increased (Table 2). (Carbon, hydrogen, and nitrogen were also measured, though no

246 clear trends with milling time were noticed [Table S1]). LC1 and LC2 had the least observed

247 pHezc change, shifting down about half a $\mathrm{pH}$ point, while the other carbons dropped 
248 approximately two $\mathrm{pH}$ points over the longest milling times. $\mathrm{BC} 1, \mathrm{BC} 2$, and $\mathrm{BC} 3$ had similar

249 PAC oxygen content around $2 \%$, and increased to $4.87 \%, 6.45 \%$, and $7.86 \%$, respectively. WD

250 had the highest initial oxygen content, 7.14\%, as well as the highest final oxygen content,

$251 \quad 10.50 \%$. CS experienced the smallest increase in oxygen content from $3.38 \%$ to $5.38 \%$. pHPZC

252 values were inversely correlated with oxygen content (Figure S2). CS, BC2, and BC3 correlated

253 with an $\mathrm{R}^{2}$ above 0.95 while $\mathrm{WD}$ and $\mathrm{BC} 1$ had $\mathrm{R}^{2}$ values of 0.90 and 0.83 , respectively. $\mathrm{A}$

254 decrease in $\mathrm{pH} P \mathrm{PC}$ and an increase in oxygen content as a result of milling have been reported

255 previously (Dunn and Knappe, 2013). The data shown here for several milling times provide

256 convincing evidence that these changes are directly caused by milling.

257

$258 \mathrm{pH}$ IEP values could be expected to decrease as did the $\mathrm{pH}$ PZC values. Interestingly, $\mathrm{pH}$ IEP did not

259 change appreciably with milling time; some variability was observed as milling progressed, but

260 overall trends were nearly flat. As such, $\mathrm{pH}$ IEP did not correlate with oxygen increases.

261 Additionally, the values were notably lower than pHPZC values, ranging from approximately 2.4

262 to 4.2 for the S-PAC of four carbons. The $\mathrm{pH}$ IEP of PAC could not be measured using the

263 electrophoretic mobility technique since the PAC particles settled too quickly; it is unknown

264 whether the $\mathrm{pH}_{\mathrm{IEP}}$ changed during the initial pass of PAC through the mill.

265

266

267

268

Table 2: Surface charge properties measured by point of zero charge, isoelectric point, and percent oxygen content. The difference between $\mathrm{pH}$ PzC and $\mathrm{pHIEP}$ is shown as $\Delta \mathrm{pH}$. Carbons are distinguished by material and milling time. Dashed lines indicate that measurements were not 269 taken.

\begin{tabular}{|c|c|c|c|c|c|c|c|c|c|}
\hline Carbon & pHpzc & pHIEP & $\Delta \mathbf{p H}$ & $\begin{array}{l}\text { Oxygen } \\
\text { Content } \\
(w / w \%)\end{array}$ & Carbon & pHpzc & pHIEP & $\Delta \mathbf{p H}$ & $\begin{array}{l}\text { Oxygen } \\
\text { Content } \\
(w / w \%)\end{array}$ \\
\hline BC1 & & & & & & & & & \\
\hline PAC & 10.37 & -- & -- & 2.41 & PAC & 6.20 & -- & -- & 7.14 \\
\hline 1 pass & 9.31 & 3.27 & 6.04 & 2.79 & 1 pass & 6.25 & 2.48 & 3.77 & 7.25 \\
\hline
\end{tabular}




\begin{tabular}{|c|c|c|c|c|c|c|c|c|c|}
\hline $15 \mathrm{~min}$ & 9.09 & 2.92 & 6.17 & 3.51 & $5 \mathrm{~min}$ & 6.03 & 2.78 & 3.25 & 7.80 \\
\hline $30 \mathrm{~min}$ & 8.92 & 2.71 & 6.21 & 4.19 & $10 \mathrm{~min}$ & 5.72 & 2.87 & 2.85 & 7.85 \\
\hline $1 \mathrm{hr}$ & 8.07 & 2.57 & 5.50 & 5.23 & $20 \mathrm{~min}$ & 5.82 & 3.06 & 2.76 & 8.30 \\
\hline $2 \mathrm{hrs}$ & 8.10 & 4.17 & 3.93 & 5.87 & $1 \mathrm{hr}$ & 5.11 & 2.67 & 2.44 & 9.15 \\
\hline $6 \mathrm{hrs}$ & 7.75 & 2.64 & 5.11 & 7.86 & $6 \mathrm{hrs}$ & 4.95 & 2.84 & 2.11 & 10.50 \\
\hline BC2 & \multicolumn{9}{|c|}{ CS } \\
\hline PAC & 8.65 & -- & -- & 2.29 & PAC & 10.79 & -- & -- & 3.38 \\
\hline 1 pass & 8.62 & 3.32 & 5.30 & 2.34 & 1 pass & 10.73 & 2.39 & 8.34 & 3.71 \\
\hline $15 \mathrm{~min}$ & 8.65 & 3.85 & 4.80 & 2.82 & 2 pass & 10.44 & 2.86 & 7.58 & 3.84 \\
\hline $30 \mathrm{~min}$ & 8.25 & 3.91 & 4.34 & 3.28 & $5 \mathrm{~min}$ & 10.57 & 3.15 & 7.42 & 3.91 \\
\hline $1 \mathrm{hr}$ & 6.78 & 3.86 & 2.92 & 3.95 & $10 \mathrm{~min}$ & 10.47 & 3.09 & 7.38 & 3.99 \\
\hline $2 \mathrm{hrs}$ & 6.7 & 3.71 & 2.99 & 5.29 & $20 \mathrm{~min}$ & 10.33 & 2.75 & 7.58 & 4.06 \\
\hline $4 \mathrm{hrs}$ & 6.42 & 3.87 & 2.55 & 5.34 & $4 \mathrm{hrs}$ & 8.00 & 3.39 & 4.61 & 5.38 \\
\hline $6.33 \mathrm{hrs}$ & 5.74 & 4.36 & 1.38 & 6.45 & \multicolumn{5}{|l|}{ LC1 } \\
\hline BC3 & & & & & PAC & 5.39 & -- & -- & 3.42 \\
\hline PAC & 9.79 & -- & -- & 1.6 & $15 \min$ & 5.52 & -- & -- & -- \\
\hline 1 pass & 9.37 & -- & -- & 2.23 & $30 \mathrm{~min}$ & 5.55 & -- & -- & -- \\
\hline $5 \mathrm{~min}$ & 9.00 & -- & -- & 2.44 & $6 \mathrm{hrs}$ & 4.85 & -- & -- & 6.76 \\
\hline $10 \mathrm{~min}$ & 8.72 & -- & -- & 2.94 & \multicolumn{5}{|l|}{ LC2 } \\
\hline $20 \mathrm{~min}$ & 8.50 & -- & -- & 3.44 & PAC & 11.58 & -- & -- & 5.52 \\
\hline $2 \mathrm{hrs}$ & 7.38 & -- & -- & 4.85 & 1 pass & 9.55 & -- & -- & -- \\
\hline \multirow[t]{4}{*}{$4 \mathrm{hrs}$} & 7.05 & -- & -- & 4.87 & $5 \mathrm{~min}$ & 9.39 & -- & -- & -- \\
\hline & & & & & $10 \mathrm{~min}$ & 9.28 & -- & -- & -- \\
\hline & & & & & $20 \mathrm{~min}$ & 9.22 & -- & -- & -- \\
\hline & & & & & $4 \mathrm{hrs}$ & 9.01 & -- & -- & 9.49 \\
\hline
\end{tabular}

272 The difference in $\mathrm{pH}$ PZC and $\mathrm{pH}$ IEP is a result of the qualities measured by each technique. The

$273 \mathrm{pH}$ drift method for $\mathrm{pHPZC}$ utilized in this study used a 48 hour equilibration time, thus allowing

274 for complete diffusion of solutes into and out of carbon pores. The pHpZC is thus a measure of

275 acidity throughout the carbon material. $\mathrm{pHIEP}$ measurements are based on electrophoretic

276 movement which is affected only by charges on the outer surface of the carbon; charged

277 functional groups within the pores should have little or no effect on $\mathrm{pH}$ IEP. There are two

278 possible mechanisms for a decreasing $\mathrm{pH}$ PZC and unchanging $\mathrm{pH}$ IEP: either chemical changes are

279 only occurring at internal sites, which are measured by $\mathrm{pH}$ PZC but not $\mathrm{pHIEP}$, or chemical changes

280 are happening rapidly at external sites, wherein all S-PAC have the same external condition and

281 the average $\mathrm{pH}$ value decreases as particle size decreases and total external surface area

282 increases. The second scenario is consistent with previous work in activated carbon where it has 
283 been reported that incomplete oxidation results in preferential oxidation on the external surface,

284 and can be indicated by measuring both pHIEP and pHpzC (Menendez et al., 1995). The low and

285 unchanging pHIEP values imply that there are similar external surface charge densities of an

286 acidic nature on all S-PAC, regardless of milling time. Correlation between $\mathrm{pH}$ shifts and

287 specific external surface area, calculated from particle size measurements, reveal that the second

288 mechanism is more likely; the difference between $\mathrm{pH}$ PZC and $\mathrm{pH}_{\mathrm{IEP}}$ is used as the correlating $\mathrm{pH}$

289 factor here and is termed $\Delta \mathrm{pH}$ (Figure 4). WD, CS, and BC2 had $\mathrm{R}^{2}$ values above 0.90 while

$290 \mathrm{BC} 1$ had a poor correlation due to an outlier point. Oxygen increases also correlated strongly

291 with specific external surface area, which is consistent with the idea that oxidation is happening

292 primarily on the external surfaces (Figure 5). The concept of an easily oxidized surface, once

293 exposed to the abrasive milling environment, is sketched in Figure 6 and shows (a) the initial

294 surface oxygen groups (b) the breakup of particles to create new external surface area, and (c)

295 the subsequent oxidation of those new surfaces.

297 Manifestation of oxygen on the outer surfaces occurs in multiple ways, such as through the

298 formation of organic surface functional groups, or through inorganic oxidation. The variety of

299 oxygen-containing surface functional groups that can occur at graphite edges in activated carbon

300 have been documented (Biniak et al., 2007; Boehm, 1994). Based on the approximate mass of

301 oxygen attached to S-PAC as a result of milling $-2-5 \%$ by weight, or $0.13-0.31 \mathrm{mmol}$ of

302 oxygen per gram of carbon - the external surface concentration of oxygen-containing functional

303 groups is on the order of $0.02 \mathrm{mmol} / \mathrm{m}^{2}$. In order to evaluate the possibility that some of the

304 oxidation was inorganic, we compared ash content to oxidation. Ash content did not change

305 appreciably as PAC was milled to S-PAC (Figure S3). Percent oxygen increase between PAC 
and S-PAC correlated well with total ash content, and even better when only considering

307 potentially reactive elements: $\mathrm{Ca}, \mathrm{Mg}, \mathrm{Zn}, \mathrm{Cu}, \mathrm{Mn}, \mathrm{Fe}$, and $\mathrm{Al}$ (Figure S4). The high correlation

308 is likely the result of thorough surface oxidation on elements evenly distributed throughout the

309 carbon matrix, however, its contribution is limited: for a concentration of divalent elements of

310 approximately $10 \mathrm{mmol}$ per gram of carbon, it is likely that only $1 \%$ of those elements would be

311 accessible on external surfaces for oxidation, or $0.01 \mathrm{mmol} / \mathrm{m}^{2}$.

\section{$313 \quad 3.4 \quad$ Carbon Physical Properties}

314 Total pore volume and distributions of volume to micropores, mesopores, and macropores

315 shifted slightly as a result of milling (Table 3). BC1, BC2, BC3 and CS increased in the

316 mesoporous fraction. BC2 increased in its macroporous fraction as well. WD had a decreased

317 mesoporous fraction and an increased macroporous fraction. Primary and sub- microporous

318 fractions - pores with diameters less than $1 \mathrm{~nm}$ (10 angstroms) and from $1 \mathrm{~nm}$ to $2 \mathrm{~nm}$,

319 respectively - were also examined due to their importance in adsorption of small molecules;

320 however, there was little difference observed with respect to increased milling time (Stoeckli et

321 al., 1993). Changes to pore volumes were not a distinct function of milling time, though it is

322 reasonable that shifts in pore volume distributions following milling will trend towards increases

323 in meso- and macroporous fractions as internal pores are opened. Most notable is the

324 development of a mesoporous fraction in the longest milled S-PAC of CS where previously there

325 was none. Typically - and CS PAC was no exception - coconut-shell based activated carbons are

326 microporous upon activation (Crittenden et al., 2005b). Thus, despite a lack of direct correlation

327 between milling and pore distribution changes to the carbons, changes were observed that may

328 still have an impact on adsorption performance. 
330 Surface areas were also generally unchanged, with the exception of WD, which decreased from

331 over $1500 \mathrm{~m}^{2} / \mathrm{g}$ to $1000 \mathrm{~m}^{2} / \mathrm{g}$. It is likely that WD had thinner pore walls than other carbons, as

332 indicated by a high specific surface area, and thus had channels that were easily crushed during

333 milling. In practice it may be possible to avoid crushing pore channels by optimizing milling

334 conditions, including reduction of milling time, operation at lower mill power, or processing at a

335 lower percent solids content.

337 Table 3: Surface area and pore volume measurements for seven activated carbons.

\begin{tabular}{|c|c|c|c|c|c|c|}
\hline Carbon & $\begin{array}{c}\text { Specific } \\
\text { Surface Area } \\
\left(\mathrm{m}^{2} / \mathbf{g}\right)\end{array}$ & $\begin{array}{c}\text { Total Pore } \\
\text { Volume } \\
\left(\mathrm{cm}^{3} / \mathrm{g}\right)\end{array}$ & $\begin{array}{c}\text { Macropore } \\
\text { Volume } \\
\left(\mathrm{cm}^{3} / \mathrm{g}\right)\end{array}$ & $\begin{array}{c}\text { Mesopore } \\
\text { Volume } \\
\left(\mathrm{cm}^{3} / \mathrm{g}\right)\end{array}$ & $\begin{array}{c}\text { Sub- } \\
\text { micropore } \\
\text { Volume } \\
\left(\mathrm{cm}^{3} / \mathrm{g}\right) \\
\end{array}$ & $\begin{array}{c}\text { Primary } \\
\text { Micropore } \\
\text { Volume } \\
\left(\mathrm{cm}^{3} / \mathrm{g}\right) \\
\end{array}$ \\
\hline \multicolumn{7}{|l|}{ BC1 } \\
\hline PAC & 644 & 0.35 & 0.04 & 0.09 & 0.08 & 0.14 \\
\hline 1 pass & 777 & 0.44 & 0.05 & 0.13 & 0.08 & 0.18 \\
\hline $15 \mathrm{~min}$ & 786 & 0.32 & 0.07 & 0.07 & 0.13 & 0.05 \\
\hline $30 \mathrm{~min}$ & 857 & 0.49 & 0.07 & 0.13 & 0.09 & 0.20 \\
\hline $1 \mathrm{hr}$ & 872 & 0.35 & 0.10 & 0.09 & 0.12 & 0.04 \\
\hline $2 \mathrm{hrs}$ & 642 & 0.53 & 0.23 & 0.15 & 0.13 & 0.03 \\
\hline $6 \mathrm{hrs}$ & 762 & 0.69 & 0.11 & 0.33 & 0.10 & 0.15 \\
\hline \multicolumn{7}{|l|}{$\mathrm{BC} 2$} \\
\hline PAC & 991 & 0.50 & 0.04 & 0.10 & 0.15 & 0.21 \\
\hline 1 pass & 917 & 0.46 & 0.03 & 0.11 & 0.16 & 0.16 \\
\hline $15 \mathrm{~min}$ & 1019 & 0.54 & 0.07 & 0.12 & 0.17 & 0.19 \\
\hline $30 \mathrm{~min}$ & 1179 & 0.67 & 0.10 & 0.19 & 0.20 & 0.18 \\
\hline $1 \mathrm{hr}$ & 1047 & 0.58 & 0.09 & 0.15 & 0.16 & 0.18 \\
\hline $2 \mathrm{hrs}$ & 1010 & 0.56 & 0.12 & 0.13 & 0.15 & 0.15 \\
\hline $4 \mathrm{hrs}$ & 997 & 0.56 & 0.14 & 0.14 & 0.10 & 0.15 \\
\hline $6.33 \mathrm{hrs}$ & 872 & 0.69 & 0.17 & 0.28 & 0.12 & 0.13 \\
\hline \multicolumn{7}{|l|}{ BC3 } \\
\hline PAC & 890 & 0.48 & 0.03 & 0.14 & 0.11 & 0.20 \\
\hline 1 pass & 931 & 0.56 & 0.08 & 0.16 & 0.15 & 0.18 \\
\hline $5 \mathrm{~min}$ & 802 & 0.43 & 0.05 & 0.12 & 0.12 & 0.15 \\
\hline $10 \mathrm{~min}$ & 881 & 0.47 & 0.05 & 0.14 & 0.13 & 0.15 \\
\hline $20 \mathrm{~min}$ & 895 & 0.51 & 0.07 & 0.16 & 0.13 & 0.16 \\
\hline $2 \mathrm{hrs}$ & 890 & 1.04 & 0.42 & 0.37 & 0.14 & 0.11 \\
\hline $4 \mathrm{hrs}$ & 798 & 0.73 & 0.19 & 0.28 & 0.10 & 0.15 \\
\hline \multicolumn{7}{|l|}{ WD } \\
\hline PAC & 1676 & 0.89 & 0.03 & 0.49 & 0.37 & 0.00 \\
\hline 1 pass & 1642 & 1.05 & 0.05 & 0.68 & 0.32 & 0.00 \\
\hline $5 \mathrm{~min}$ & 1575 & 0.99 & 0.06 & 0.63 & 0.31 & 0.00 \\
\hline \multirow[t]{2}{*}{$10 \mathrm{~min}$} & 1542 & 0.96 & 0.07 & 0.60 & 0.30 & 0.00 \\
\hline & & & 17 & & & \\
\hline
\end{tabular}




\begin{tabular}{|c|c|c|c|c|c|c|}
\hline $20 \mathrm{~min}$ & 1521 & 0.91 & 0.06 & 0.55 & 0.29 & 0.02 \\
\hline $1 \mathrm{hr}$ & 1269 & 0.89 & 0.13 & 0.45 & 0.23 & 0.09 \\
\hline $6 \mathrm{hrs}$ & 1008 & 0.84 & 0.28 & 0.29 & 0.25 & 0.02 \\
\hline \multicolumn{7}{|l|}{ CS } \\
\hline PAC & 906 & 0.47 & 0.12 & 0.00 & 0.09 & 0.26 \\
\hline 1 pass & 1134 & 0.49 & 0.04 & 0.01 & 0.15 & 0.28 \\
\hline 2 pass & 895 & 0.39 & 0.03 & 0.02 & 0.12 & 0.23 \\
\hline $5 \min$ & 932 & 0.42 & 0.04 & 0.02 & 0.13 & 0.23 \\
\hline $10 \mathrm{~min}$ & 938 & 0.42 & 0.05 & 0.01 & 0.14 & 0.23 \\
\hline $20 \mathrm{~min}$ & 1047 & 0.46 & 0.08 & 0.00 & 0.16 & 0.22 \\
\hline $4 \mathrm{hrs}$ & 1050 & 0.50 & 0.09 & 0.09 & 0.17 & 0.15 \\
\hline \multicolumn{7}{|l|}{ LC1 } \\
\hline PAC & 660 & 0.61 & 0.08 & 0.36 & 0.05 & 0.12 \\
\hline $15 \mathrm{~min}$ & -- & -- & -- & -- & -- & -- \\
\hline $30 \mathrm{~min}$ & -- & -- & -- & -- & -- & -- \\
\hline $6 \mathrm{hrs}$ & 713 & 0.69 & 0.12 & 0.40 & 0.06 & 0.12 \\
\hline \multicolumn{7}{|l|}{ LC2 } \\
\hline PAC & 505 & 0.39 & 0.05 & 0.19 & 0.04 & 0.11 \\
\hline 1 pass & -- & -- & -- & -- & -- & -- \\
\hline $5 \mathrm{~min}$ & -- & -- & -- & -- & -- & -- \\
\hline $10 \mathrm{~min}$ & -- & -- & -- & -- & -- & -- \\
\hline $20 \mathrm{~min}$ & -- & -- & -- & -- & -- & -- \\
\hline $4 \mathrm{hrs}$ & 555 & 0.56 & 0.14 & 0.33 & 0.08 & 0.01 \\
\hline
\end{tabular}

\subsection{Comparison with S-PAC in Literature}

341 A handful of publications over the past decade have explored milled carbon for use as an

342 adsorbent; however, since most of these studies focus on adsorption performance, few have

343 reported detailed physical and chemical carbon characteristics differences (Ando et al., 2010;

344 Dunn and Knappe, 2013; Ellerie et al., 2013; Heijman et al., 2009b; Matsui et al., 2005, 2015,

$3452014,2013,2009,2008,2007)$. Available characterization data was extracted from those

346 publications and is presented in Table 4. Here we consider all reported carbons with sizes under

347 one micrometer. All studies reported particle size, which have been measured by various

348 techniques, including dynamic light scattering (DLS), laser light scattering (LLS), laser

349 diffraction, LED measurement, and optical and scanning electron microscopy. After particle size,

350 surface area, as measured by nitrogen adsorption, was the next most common parameter 
351 reported. Since particle size and surface area are two characteristics often used to describe

352 performance of PAC, reporting of these parameters is logical. Some papers have reported carbon

353 characteristics not examined in this study, including uniformity coefficient and geometric

354 standard deviation as related to particle size (Matsui et al., 2013), as well as acidic and basic

355 functional groups as determined by Boehm titration (Matsui et al., 2015). The next most

356 commonly reported parameters regard micropore fractions and mesopore fractions, though

357 reporting is inconsistent; some studies report the volume of the pore fraction while others report

358 the surface area of the pore fraction. The total pore volume is rarely reported. Lastly, pHpzc has

359 only been reported by Ellerie et al. (2013) and Dunn and Knappe (2013). Notably, only Dunn

360 and Knappe (2013) have reported oxygen content (not included in Table 4). It is clear that data

361 gaps exist for an analysis of S-PAC beyond particle size and select physical characteristics.

362

363 Another data gap lies in the reporting of milling parameters. No paper has discussed the details

364 of milling beyond a description of the grinding media and, in one case, the milling duration. It is

365 clear from the number of variables present in wet milling, and the variety of carbons produced in

366 this study, that processing details are important to reproducible data. For this reason, grinding is

367 often viewed as an art, rather than a science. The most critical information to be reported relate

368 to the transfer of energy: mill speed, milling duration, grinding media characteristics (size,

369 composition, and loading rate), grinding carrier fluid plus dispersants used, and carbon loading

370 rate (percent solids content). However, it is likely that all process variables play some role or

371 another towards the final outcome, thus it is recommended that as many details be reported as

372 possible, including such parameters as mill configuration, rate of flow, and temperature of

373 milling. 
375 The studies in Table 4 have found S-PAC to perform well, despite having few characterization

376 parameters. It is understood that the improved rate of small molecular adsorption is governed by

377 the path length, which is determined by particle size, a parameter that is reported in each study.

378 However, the changes to chemical and physical characteristics observed in this study, and which

379 likely have also occurred in carbons produced for previous studies, are known to have effects on

380 adsorption. The increasingly negative surface charges observed could result in shifts in the

381 adsorption affinity for hydrophobic compounds. Increases in the mesoporous and macroporous

382 fractions would increase the adsorption capacity for lower molecular weight NOM. Lastly,

383 optimization of S-PAC production is an important consideration. Between highly variable

384 grinding procedures and the heterogeneity of activated carbon, an S-PAC with particular

385 characteristics is produced. Additionally, extended milling yielded diminishing returns, thus

386 there is a tradeoff between energy input and production of a useful S-PAC. Material choice is

387 another major design consideration; for example, the lignite coals in this study reached small

388 sizes very quickly, but the bituminous coals were more predictable in breakdown. An

389 understanding of the grinding parameters and parent PAC that produce certain S-PAC types will

390 result in the ability to fine tune the process for creating an S-PAC with certain desired

391 characteristics. 


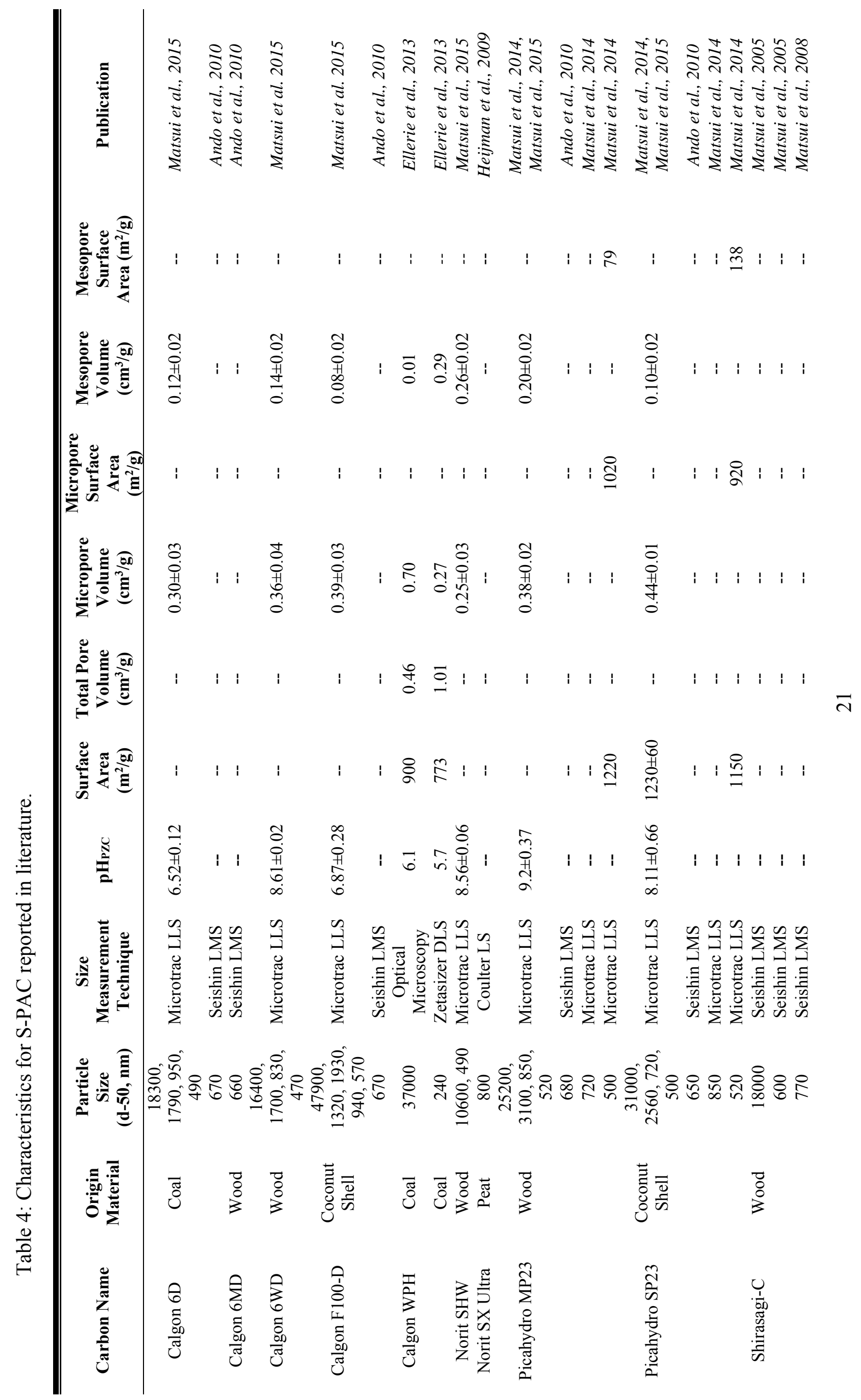




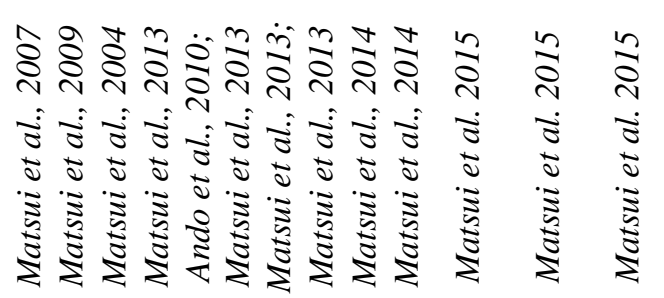

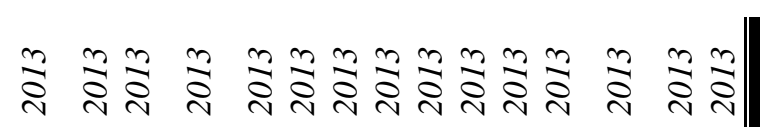

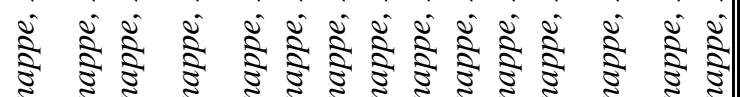
过运这这这这这这

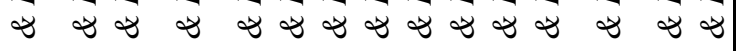

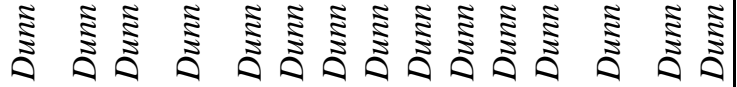

i $\quad 1 \quad 1 \quad 1 \quad 1 \quad$ 志

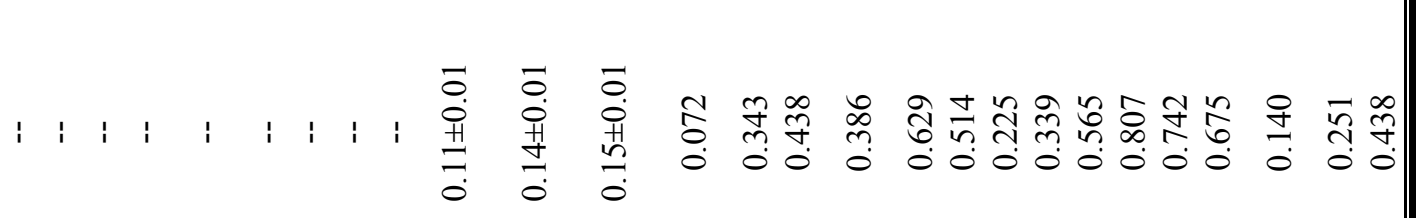

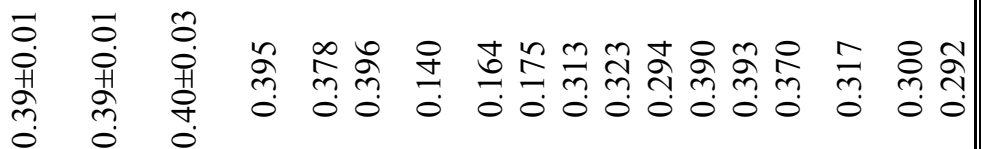

$\begin{array}{lllllllll} & 1 & 1 & 1 & 1 & 1 & 1 & 1 & 1\end{array}$

$\begin{array}{lllllllllllllll}1 & 1 & 1 & 1 & 1 & 1 & 1 & 1 & 1 & 1 & 1 & 1 & 1 & 1 & 1\end{array}$

N

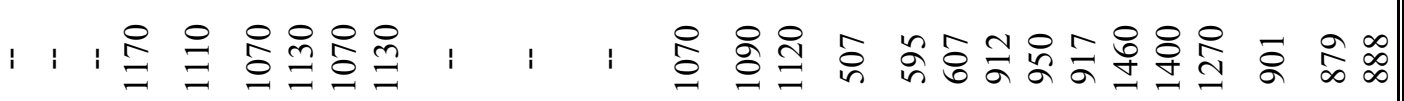

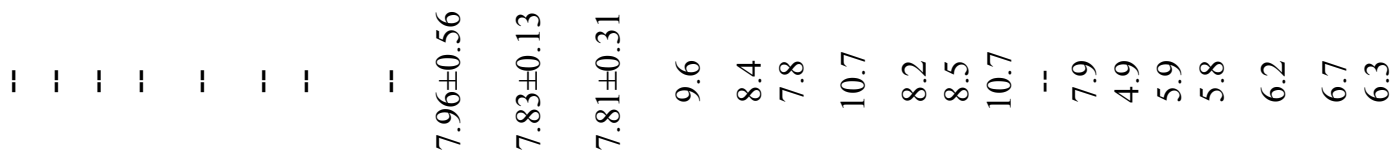

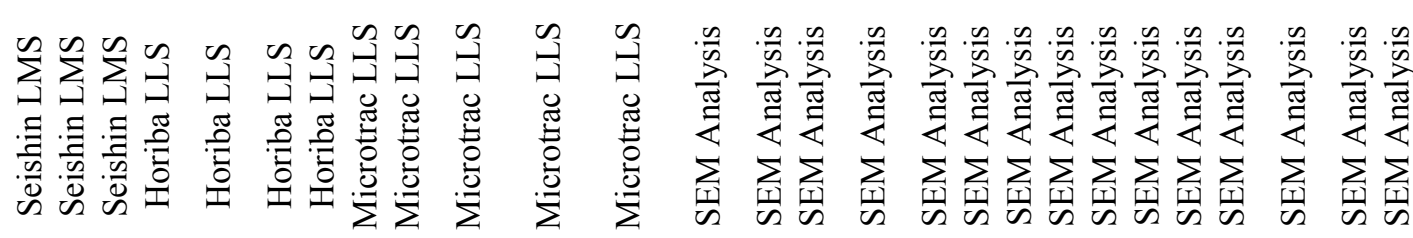

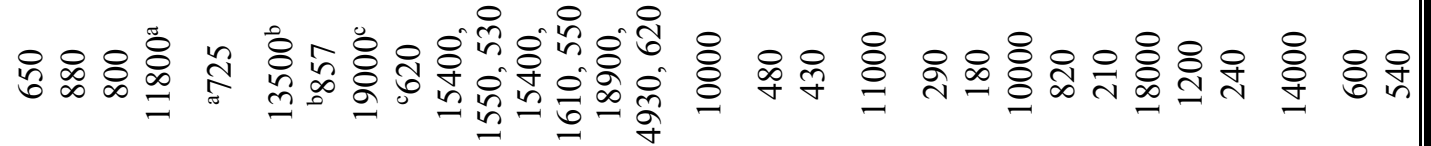

8
8
3

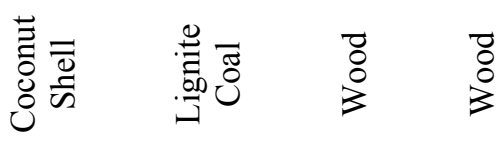

章

3
$\frac{1}{0}$
$\frac{1}{\pi}$

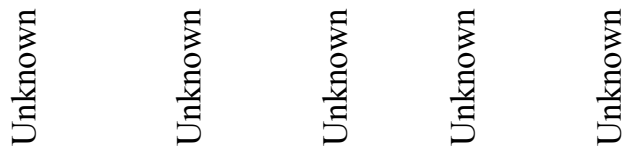




\section{Conclusions}

The primary conclusions from this study are as follows:

- Pulverization of activated carbon by bead milling predictably reduces the mean particle size. The ability to reduce in size was generally related to the carbon precursor material; we observed faster size decline in the coal-derived carbons; however, we recognize that other wood and coconut shell carbons may behave differently than the samples used here. Successful pulverization in all carbon types supports the potential of S-PAC technology for application.

- Chemical property measurements led to discovery of an oxidative process occurring during bead milling. Oxidation appears to be most prevalent on external surfaces and the extent of surface oxidation did not increase with milling time. Since surface charge is known to affect adsorption processes, oxidation due to bead milling may affect S-PAC performance in relation to its parent PAC.

- Pore volume and surface area changes were not a predictable function of milling time; clear trends across all carbon types were not apparent. However, some changes in individual samples - particularly shifts towards meso- and macroporous fraction - are likely significant enough to affect adsorption performance in systems with competitive adsorption.

- Material reporting is lacking among S-PAC studies. Improved reporting of material processing and characteristics would improve the ability to predict which carbon materials will be easiest to mill and what surface chemistry changes to expect. This will enable more accurate design of future S-PAC processes. 


\section{Acknowledgements}

This research is sponsored by a grant from the National Science Foundation, CBET-1236070.

SEM images were created at the Clemson University Electron Microscopy Laboratory. Ian

DeMass is thanked for assistance with particle characterization.

\section{References}

Akmil Başar, C., Karagunduz, A., Keskinler, B., Cakici, A., 2003. Effect of presence of ions on surface characteristics of surfactant modified powdered activated carbon (PAC). Appl. Surf. Sci. 218, 170-175. doi:10.1016/S0169-4332(03)00576-2

Ando, N., Matsui, Y., Kurotobi, R., Nakano, Y., Matsushita, T., Ohno, K., 2010. Comparison of natural organic matter adsorption capacities of super-powdered activated carbon and powdered activated carbon. Water Res. 44, 4127-4136.

Apul, O.G., Wang, Q., Zhou, Y., Karanfil, T., 2013. Adsorption of aromatic organic contaminants by graphene nanosheets: comparison with carbon nanotubes and activated carbon. Water Res. 47, 1648-54. doi:10.1016/j.watres.2012.12.031

Apul, O.G., Zhou, Y., Karanfil, T., 2015. Mechanisms and modeling of halogenated aliphatic contaminant adsorption by carbon nanotubes. J. Hazard. Mater. 295, 138-144. doi:10.1016/j.jhazmat.2015.04.030

ASTM Standard D5158-98, 2013. Standard Test Method for Determination of Particle Size of Powdered Activated Carbon by Air Jet Sieving. ASTM International, West Conshohocken, PA.

Biniak, S., Pakula, M., Szymanski, G., Swiatkowski, A., 1999. Effect of activated carbon surface oxygen-and/or nitrogen-containing groups on adsorption of copper (II) ions from aqueous solution. Langmuir 15, 6117-6122.

Biniak, S., Swiatkowski, A., Pakula, Mc.\& P. of C., 2007. Electrochemical Studies of Phenomena at Active Carbon-Electrolyte Solution Interfaces, in: Radovic, L. (Ed.), Chemistry \& Physics of Carbon. CRC Press, pp. 125-216.

Boehm, H., 1994. Some aspects of the surface chemistry of carbon blacks and other carbons. Carbon N. Y. 32, 759-769.

Clark, R., Lykins, B., 1990. Granular activated carbon: design, operation and cost. Lewis Publishers, Chelsea, MI. 
Crittenden, J.C., Trussell, R.R., Hand, D.W., Howe, K.J., Tchobanoglous, G., 2005a. Water Quality Management Strategies, in: Water Treatment: Principles and Design. pp. 221-286.

Crittenden, J.C., Trussell, R.R., Hand, D.W., Howe, K.J., Tchobanoglous, G., 2005 b. Adsorption, in: Water Treatment: Principles and Design. John Wiley \& Sons, Inc., Hoboken, NJ, pp. 1245-1358.

Dastgheib, S.A., Karanfil, T., Cheng, W., 2004. Tailoring activated carbons for enhanced removal of natural organic matter from natural waters. Carbon N. Y. 42, 547-557. doi:10.1016/j.carbon.2003.12.062

Dunn, S.E., Knappe, D.R.U., 2013. DBP Precursor and Micropollutant Removal by Powdered Activated Carbon (Web Report \#4294). Water Research Foundation, Denver, Colorado.

Ellerie, J.R., Apul, O.G., Karanfil, T., Ladner, D.A., 2013. Comparing graphene, carbon nanotubes, and superfine powdered activated carbon as adsorptive coating materials for microfiltration membranes. J. Hazard. Mater. 261C, 91-98. doi:10.1016/j.jhazmat.2013.07.009

Greenbank, M., Spotts, S., 1993. Effects of starting material on activated carbon characteristics and performance. Proc. WATERTECH Expo.

Heijman, S.G.J., Hamad, J.Z., Kennedy, M.D., Schippers, J., Amy, G., 2009a. Submicron powdered activated carbon used as a pre-coat in ceramic micro-filtration. Desalin. Water Treat. 9, 86-91.

Heijman, S.G.J., Rabinovitch, E., Bos, F., Olthof, N., van Dijk, J.C., 2009b. Sustainable seawater desalination: Stand-alone small scale windmill and reverse osmosis system. Desalination 248, 114-117.

Hernández, A.M., Labady, M., Laine, J., 2014. Granular Activated Carbon from Wood Originated from Tropical Virgin Forest. Open J. For. 4, 208-211.

Heschel, W., Klose, E., 1995. On the suitability of agricultural by-products for the manufacture of granular activated carbon. Fuel 74, 1786-1791. doi:10.1016/0016-2361(95)80009-7

Jia, Y.F., Thomas, K.M., 2000. Adsorption of Cadmium Ions on Oxygen Surface Sites in Activated Carbon. Langmuir 16, 1114-1122. doi:10.1021/la990436w

Karanfil, T., Kilduff, J.E., 1999. Role of Granular Activated Carbon Surface Chemistry on the Adsorption of Organic Compounds . 1 . Priority Pollutants 33, 3217-3224.

Karanfil, T., Kitis, M., Kilduff, J.E., Wigton, A., 1999. Role of granular activated carbon surface chemistry on the adsorption of organic compounds. 2. Natural organic matter. Environ. Sci. Technol. 33, 3225-3233. 
Li, L., Quinlivan, P.A., Knappe, D.R.U., 2002. Effects of activated carbon surface chemistry and pore structure on the adsorption of organic contaminants from aqueous solution. Carbon N. Y. 40, 2085-2100.

Liu, G., Ma, J., Li, X., Qin, Q., 2009. Adsorption of bisphenol A from aqueous solution onto activated carbons with different modification treatments. J. Hazard. Mater. 164, 1275-80. doi:10.1016/j.jhazmat.2008.09.038

Lopez-Ramon, M., Stoeckli, F., Moreno-Castilla, C., Carrasco-Marín, F., 1999. On the characterization of acidic and basic surface sites on carbons by various techniques. Carbon N. Y. 37, 1215-1221.

Matsui, Y., Aizawa, T., Kanda, F., Nigorikawa, N., Mima, S., Kawase, Y., 2007. Adsorptive removal of geosmin by ceramic membrane filtration with super-powdered activated carbon. J. Water Supply Res. Technol. 56, 411. doi:10.2166/aqua.2007.017

Matsui, Y., Ando, N., Sasaki, H., Matsushita, T., Ohno, K., 2009. Branched pore kinetic model analysis of geosmin adsorption on super-powdered activated carbon. Water Res. 43, 3095103. doi:10.1016/j.watres.2009.04.014

Matsui, Y., Murai, K., Sasaki, H., Ohno, K., Matsushita, T., 2008. Submicron-sized activated carbon particles for the rapid removal of chlorinous and earthy-musty compounds. J. Water Supply Res. Technol. 57, 577. doi:10.2166/aqua.2008.070

Matsui, Y., Murase, R., Sanogawa, T., Aoki, N., Mima, S., Inoue, T., Matsushita, T., 2005. Rapid adsorption pretreatment with submicrometre powdered activated carbon particles before microfiltration. Water Sci. Technol. 51, 249-56.

Matsui, Y., Nakao, S., Sakamoto, A., Taniguchi, T., Pan, L., Matsushita, T., Shirasaki, N., 2015. Adsorption capacities of activated carbons for geosmin and 2-methylisoborneol vary with activated carbon particle size: Effects of adsorbent and adsorbate characteristics. Water Res. 85, 95-102. doi:10.1016/j.watres.2015.08.017

Matsui, Y., Nakao, S., Taniguchi, T., Matsushita, T., 2013. Geosmin and 2-methylisoborneol removal using superfine powdered activated carbon: shell adsorption and branched-pore kinetic model analysis and optimal particle size. Water Res. 47, 2873-80. doi:10.1016/j.watres.2013.02.046

Matsui, Y., Sakamoto, A., Nakao, S., Taniguchi, T., Matsushita, T., Shirasaki, N., Sakamoto, N., Yurimoto, H., 2014. Isotope Microscopy Visualization of the Adsorption Profile of 2Methylisoborneol and Geosmin in Powdered Activated Carbon. Environ. Sci. Technol. 48, 10897-10903.

Menendez, J., Illán-Gómez, M., Radovic, L., 1995. On the difference between the isoelectric point and the point of zero charge of carbons. Carbon N. Y. 33, 1655-1657. 
Mohd Din, A.T., Hameed, B.H., Ahmad, A.L., 2009. Batch adsorption of phenol onto physiochemical-activated coconut shell. J. Hazard. Mater. 161, 1522-1529. doi:10.1016/j.jhazmat.2008.05.009

Neely, J., Isacoff, E., 1982. Carbonaceous adsorbents for the treatment of ground and surface waters: Vol. 21. Pollution Engineering and Technology. Marcel Dekker Inc., New York, United States.

Osantowski, R., Wullschleger, R., 1986. Evaluation of Activated Carbon for Enhanced COD Removal from Pharmaceutical Wastewater. U.S. EPA, Cincinnati, OH.

Patni, A., Ludlow, D., Adams, C., 2008. Characteristics of ground granular activated carbon for rapid small-scale column tests. J. Environ. Eng. 216-221.

Pelekani, C., Snoeyink, V.L., 2000. Competitive adsorption between atrazine and methylene blue on activated carbon: the importance of pore size distribution. Carbon N. Y. 38, 1423-1436. doi:10.1016/S0008-6223(99)00261-4

Pendleton, P., Wong, S.H., Schumann, R., Levay, G., Denoyel, R., Rouquero, J., 1997. Properties of activated carbon controlling 2-Methylisoborneol adsorption. Carbon N. Y. 35, 1141-1149. doi:10.1016/S0008-6223(97)00086-9

Quinlivan, P. a, Li, L., Knappe, D.R.U., 2005. Effects of activated carbon characteristics on the simultaneous adsorption of aqueous organic micropollutants and natural organic matter. Water Res. 39, 1663-73. doi:10.1016/j.watres.2005.01.029

Snoeyink, V.L., Chen, A.S.C., 1985. Removal of Organic Micropollutants by Coagulation and Adsorption. Sci. Total Environ. 47, 155-167.

Stoeckli, F., Huguenin, D., Greppi, A., 1993. Primary and secondary filling of micropores in active carbons. J. Chem. Soc. Faraday Trans. 89, 2055. doi:10.1039/ft9938902055

Tessmer, C.H., Vidic, R.D., Uranowski, L.J., 1997. Impact of Oxygen-Containing Surface Functional Groups on Activated Carbon Adsorption of Phenols. Environ. Sci. Technol. 31, 1872-1878. doi:10.1021/es960474r

Toles, C.A., Marshall, W.E., Johns, M.M., Wartelle, L.H., McAloon, A., 2000. Acid-activated carbons from almond shells: physical, chemical and adsorptive properties and estimated cost of production. Bioresour. Technol. 71, 87-92. doi:10.1016/S0960-8524(99)00029-2

Yalcin, M., Arol, A.I., 2002. Gold cyanide adsorption characteristics of activated carbon of noncoconut shell origin. Hydrometallurgy 63, 201-206. doi:10.1016/S0304-386X(01)00203-1 


\section{Figure Captions}

Figure 1: Particle size of milled carbons with milling times varied from one pass through the mill to 6.3 hours. Data are split into two panes to avoid excessive overlap.

Figure 2: Scanning electron microscopy images (10K magnification) of all forms of BC1, including (A) PAC and all S-PACs. Particles visibly decrease in size as milling increases from (B) 1 pass to (C) $15 \mathrm{~min}$, (D) $30 \mathrm{~min}$, (E) $1 \mathrm{hr}$, (F) $2 \mathrm{hrs}$, and (G) $6 \mathrm{hrs}$.

Figure 3: Concentration of particles increases as particle size decreases. Concentrations were calculated from measured average particle sizes and conservation of mass.

Figure 4: The difference between $\mathrm{pH}$ measured using the pHPZC method and the electrokinetic measurement of the isoelectric point is correlated with the S-PAC external surface area, which increases as particle size decreases.

Figure 5: Oxygen increased with newly revealed surface area as a result of milling. External surface area was calculated from Z-avg particle size measurements.

Figure 6: Illustration of PAC pulverization into S-PAC with proposed rapid surface oxidation. 
Figure 1

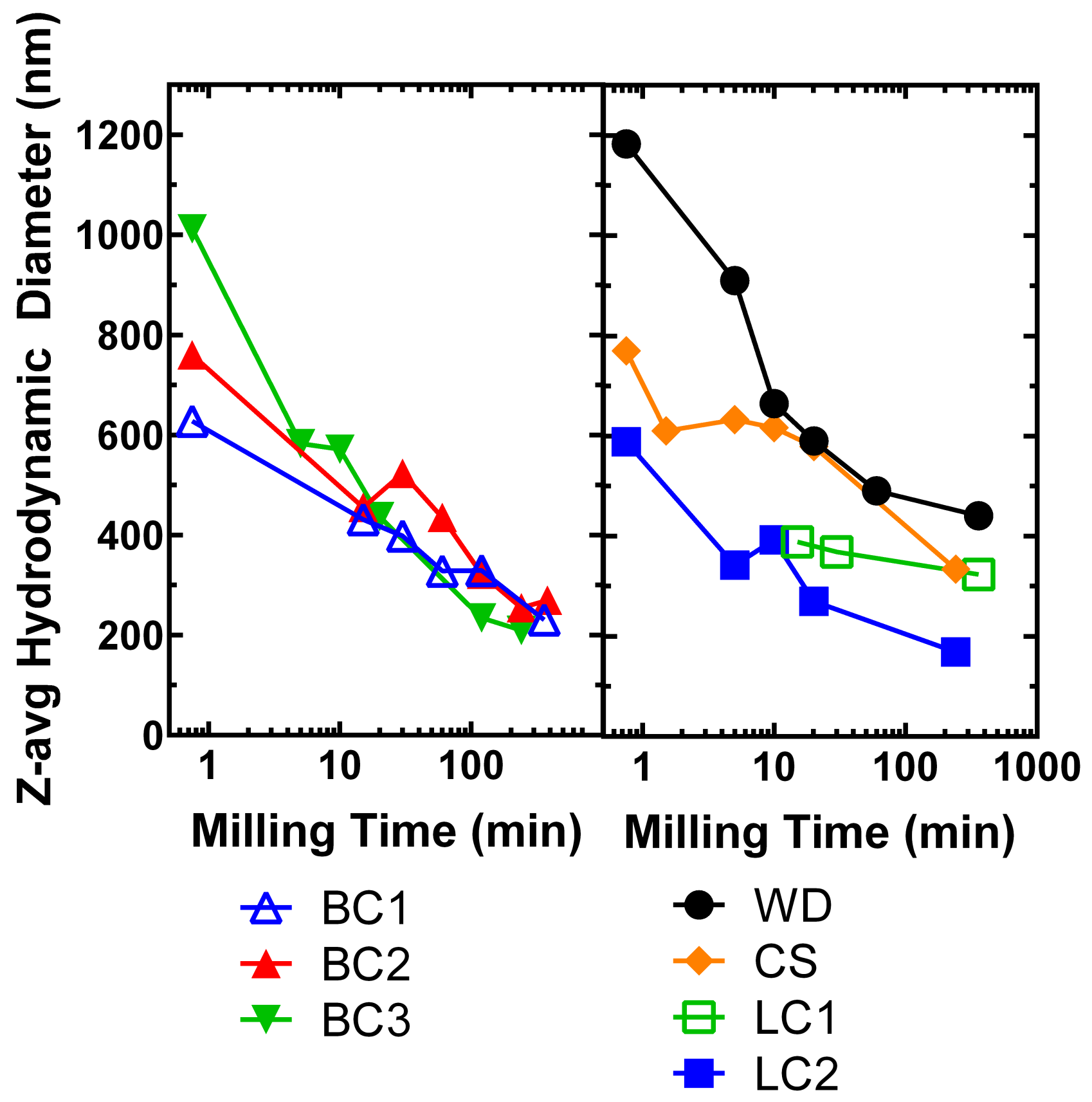


Figure 2
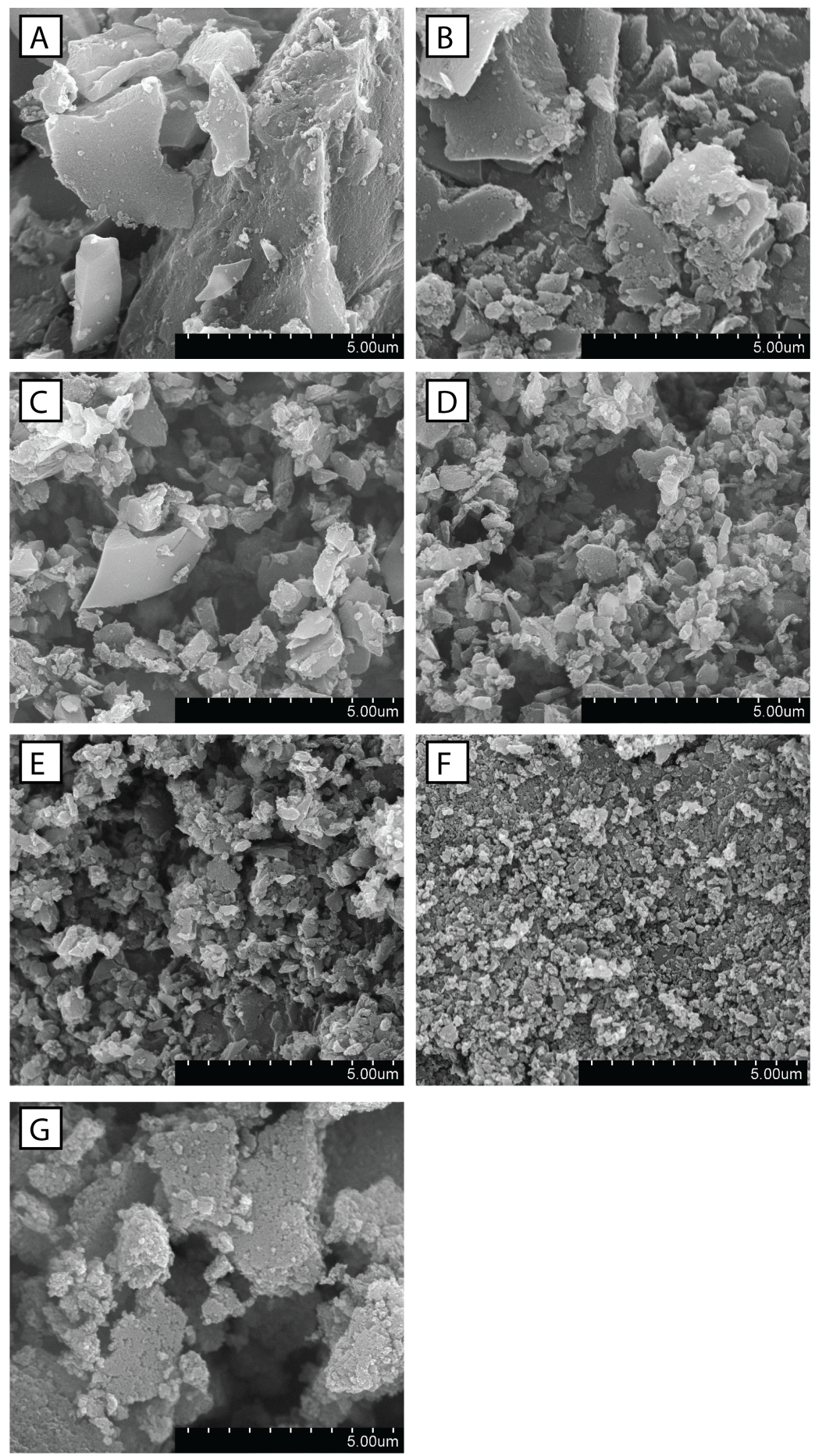
Figure 3

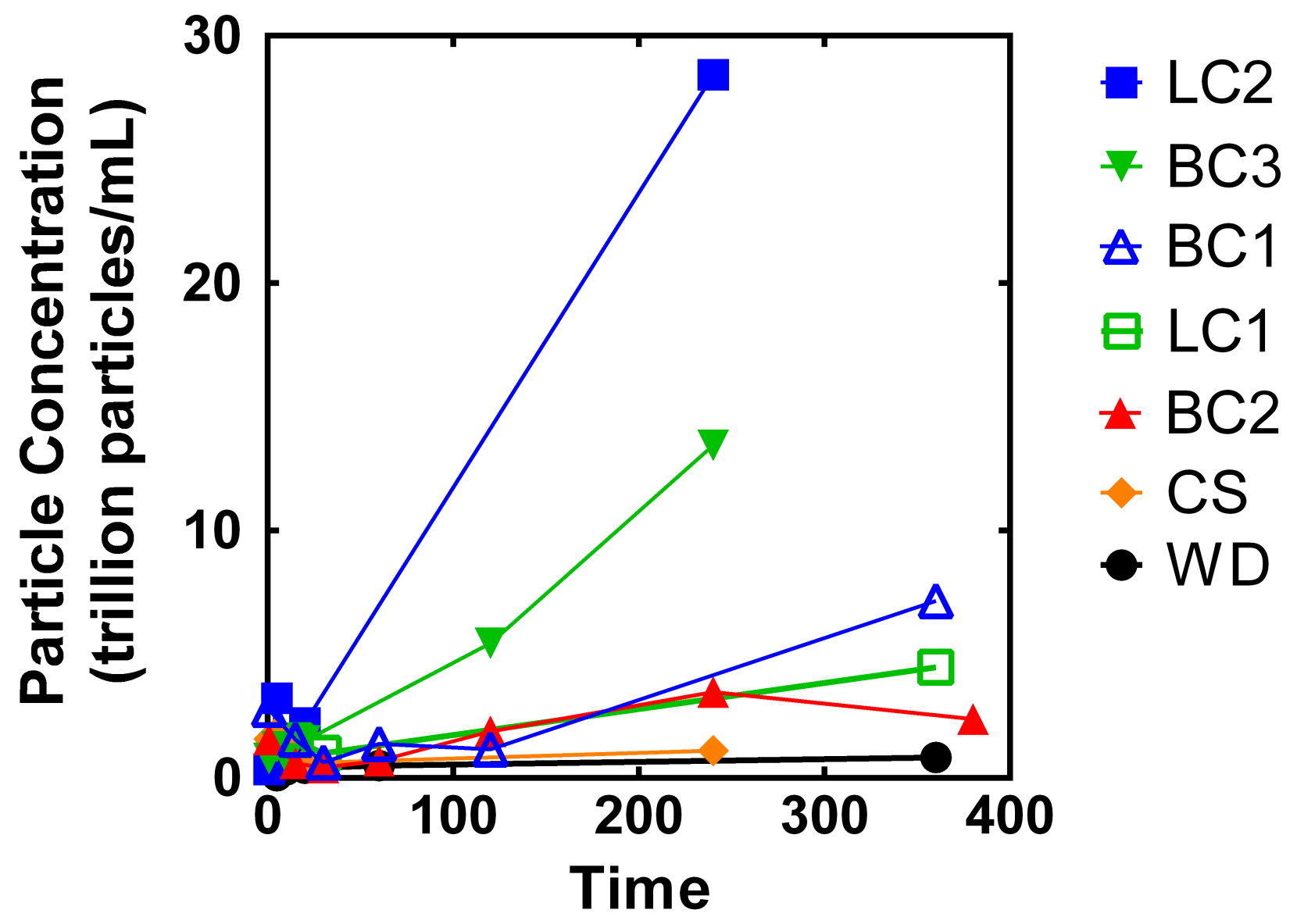




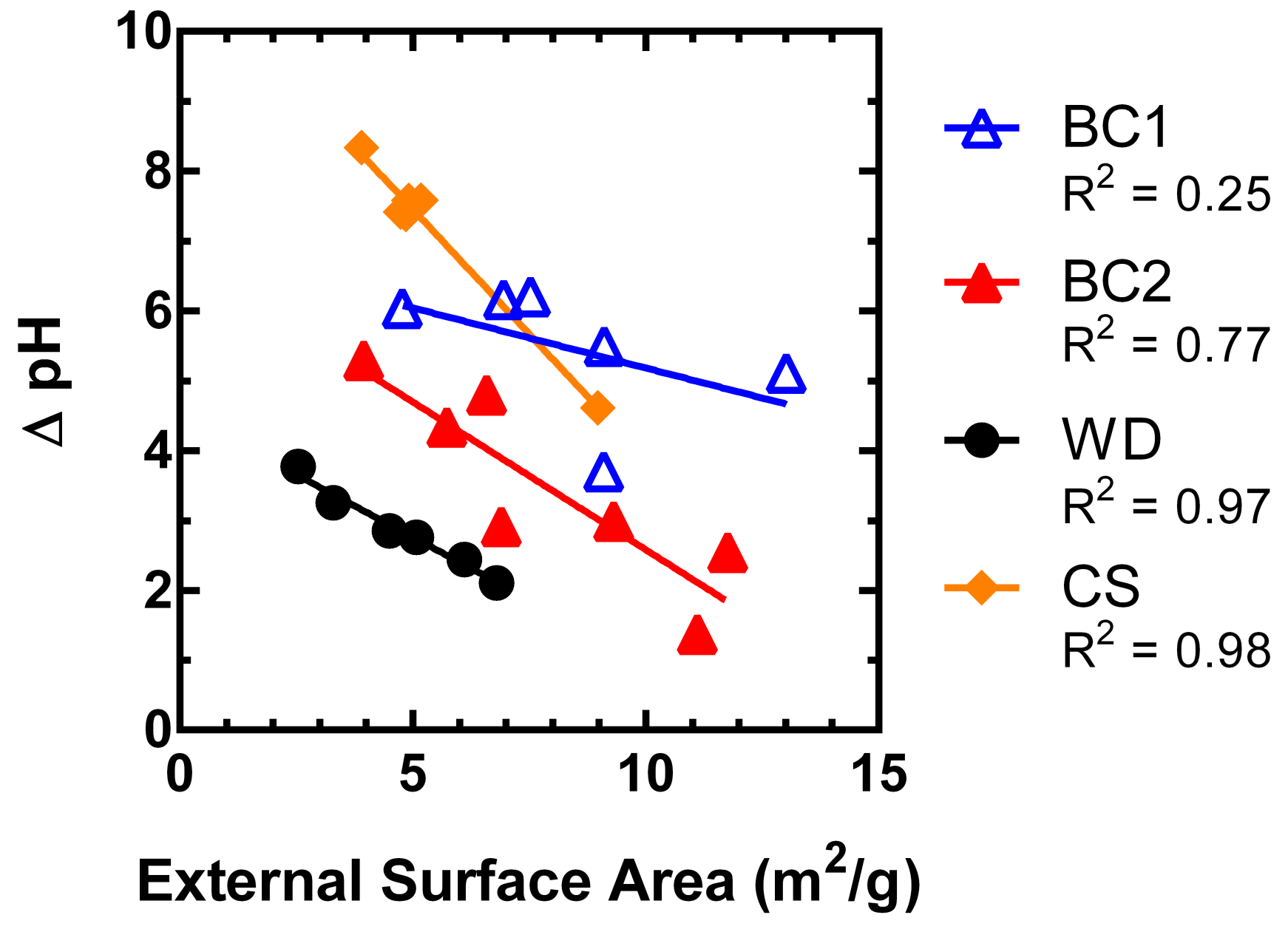




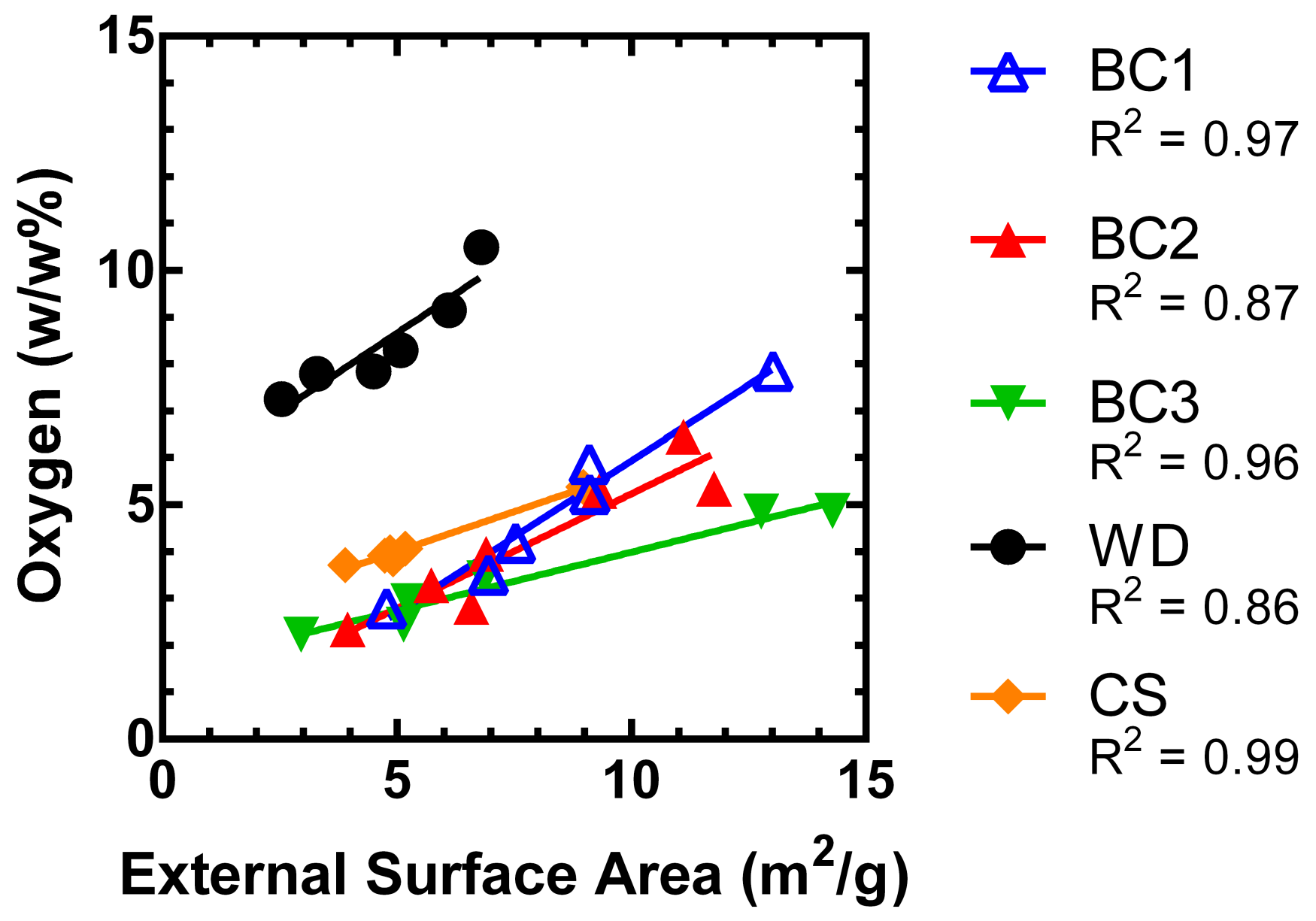




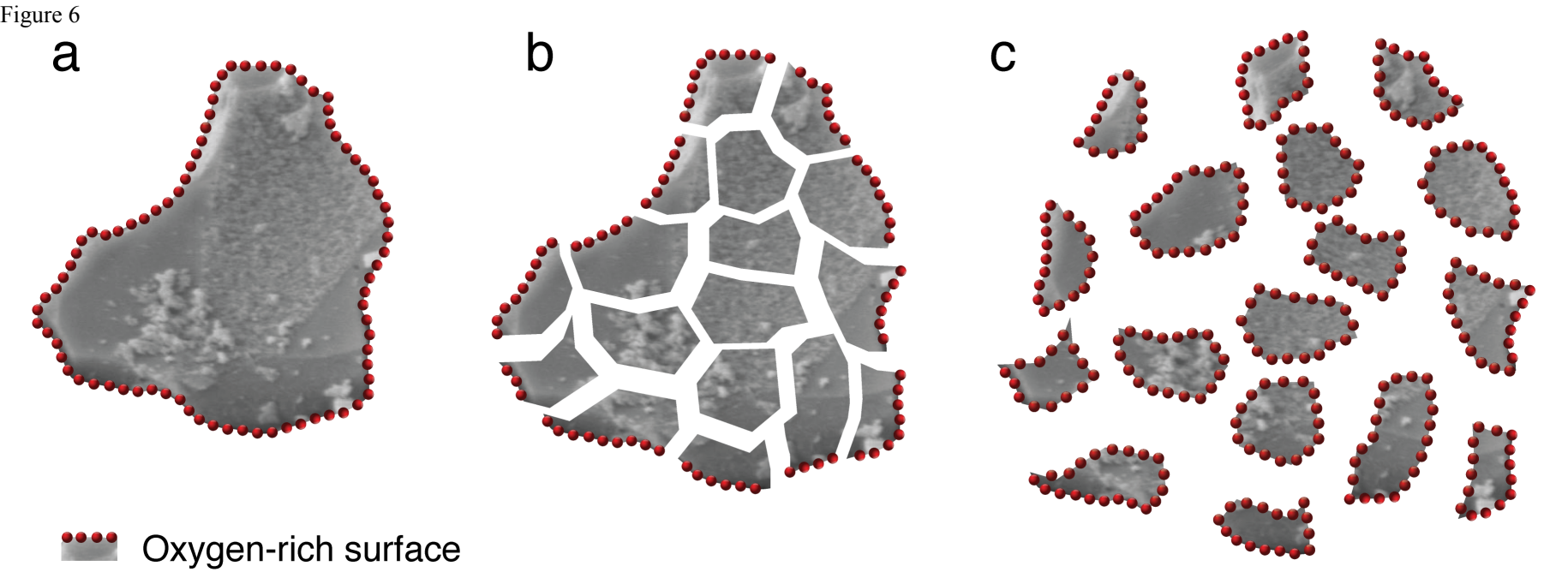




\section{Wet milling process}
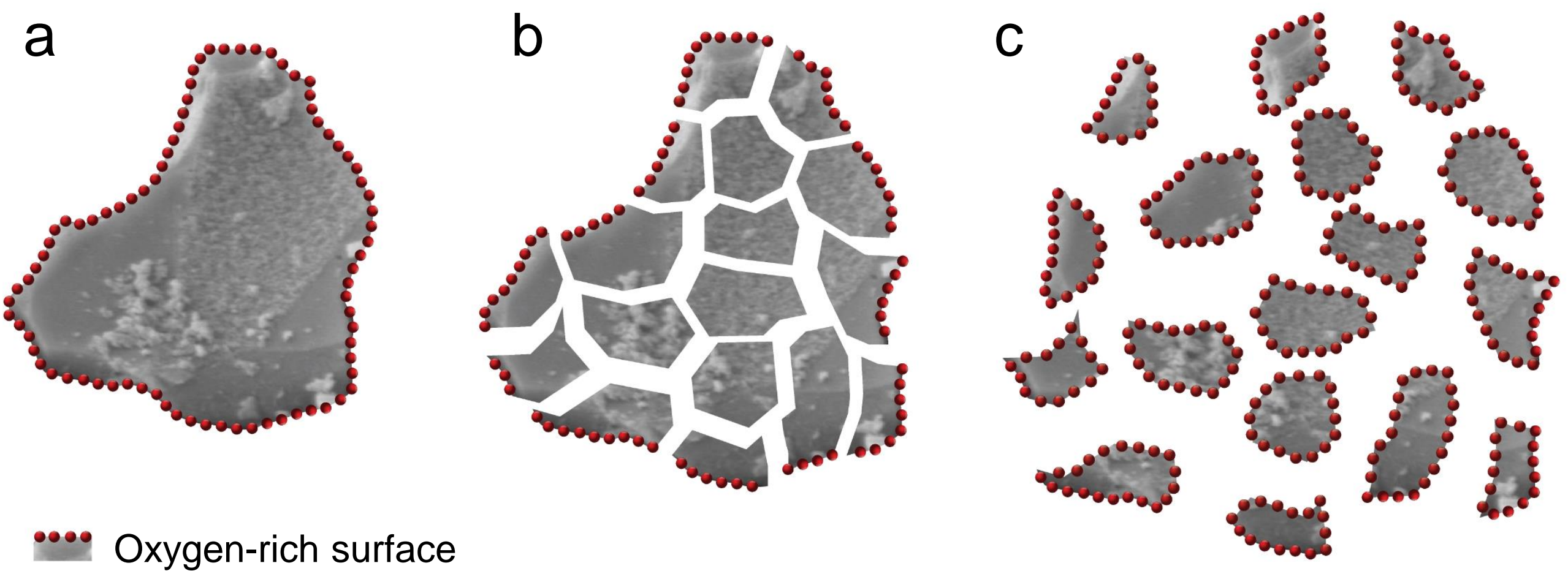